\title{
Engage and Conquer: An Online Empirical Approach into Whether Intrinsic or Extrinsic Motivation Leads to More Enhanced Students' Engagement
}

\author{
Catherine Kanellopoulou, Andreas Giannakoulopoulos \\ Department of Audio and Visual Arts, Ionian University, Corfu, Greece \\ Email: catherine.kanellopoulou@gmail.com,agsp96@gmail.com
}

How to cite this paper: Kanellopoulou, C., \& Giannakoulopoulos, A. (2020). Engage and Conquer: An Online Empirical Approach into Whether Intrinsic or Extrinsic Motivation Leads to More Enhanced Students' Engagement. Creative Education, 11, 143-165.

https://doi.org/10.4236/ce.2020.112011

Received: January 21, 2020

Accepted: February 24, 2020

Published: February 27, 2020

Copyright $\odot 2020$ by author(s) and Scientific Research Publishing Inc. This work is licensed under the Creative Commons Attribution International License (CC BY 4.0).

http://creativecommons.org/licenses/by/4.0/

\begin{abstract}
This paper reviews research literature in the area of student engagement and motivation and discusses the findings of an experiment which examined the effects of intrinsic and extrinsic motivation on the learning process of foreign language vocabulary with the use of a film extract. The extract was part of an online specially-built platform designed to enhance students' engagement through a series of interactive activities. The article focuses on the relationship between motivation and engagement and looks into the differences in performance between students who are more intrinsically or extrinsically motivated. Based on our findings, we argue that intrinsic motivation leads to more active engagement on the part of learners, which is a pathway to deeper learning and better academic achievements in foreign language learning.
\end{abstract}

\section{Keywords}

Student Engagement, Foreign Language Learning, Intrinsic Motivation, Extrinsic Motivation, Online Foreign Language Learning

\section{Introduction}

The chief impediments to learning are not cognitive. It is not that students cannot learn; it is that they do not wish to (Csikszentmihalyi, 1990b).

Curiosity is a basic element of human nature and a key element of our cognition (Kidd \& Hayden, 2015). Young children love to play and learn new things. They are curious and eager to actively engage in their environment and with doing so, they inevitably learn. Generally, when people willingly engage in new 
learning activities, we consider them genuinely motivated and as a rule their motivated behaviour results in acquiring new knowledge about the world that surrounds them.

Our interest in the role of motivation in foreign language vocabulary learning is grounded in the belief that acquiring new vocabulary is crucial in language development and fluency. A rich vocabulary will help foreign language learners develop their reading and listening skills faster and more effectively, as well as allow them more fluency in their speaking and writing. It is, therefore, important for researchers and educators alike to focus on how to actively engage students, or increase their motivation, in order to optimise their learning potentials. These two concepts should be studied together as the one seems to be the result of the other; however, available research mainly deals with either engagement or motivation, instead of considering the two elements simultaneously (Malhiwsky, 2010). A key starting point, then, would be to define engagement with respect to the learning environment and then look into how to motivate learners so that engagement is achieved.

\section{What Is Engagement?}

Although "student engagement" has enjoyed considerable attention in the literature over the last 20 years (Trowler, 2010), researchers have not been able to clearly define it as a concept mainly because of its many dimensions; academic, cognitive, intellectual, institutional, emotional, behavioural, social, and psychological to name a few (Parsons \& Taylor, 2011). Trowler (2010) defines student engagement as being "concerned with the interaction between the time, effort and other relevant resources invested by both students and their institutions intended to optimise the student experience and enhance the learning outcomes and development of students and the performance, and reputation of the institution".

Trowler's (2010) literature search on "student engagement" produced about 1,000 pieces of work in which most of the literature came from the US and Australia, where student engagement has been studied mainly via national surveys. These results have boosted existing research on student involvement which started back in the 1980s, aiming at underlining the validity and reliability of the concept.

Literature from the UK, on the other hand, mainly focused on tools, for example virtual learning environments, techniques like a particular type of feedback or approaches to a particular situation such distant learning.

Looking back in the 1980's, Astin (1984) laid the foundations for the student engagement concept when he proposed his theory of student involvement (SI), defined as the quantity and quality of physical and psychological energy that a student invests in the college experience. What was groundbreaking in his SI theory is that attention was no longer on subject matter and technique but on the motivation and behaviour of the student. According to his theory, the effectiveness of any educational policy or practice is directly related to the capacity of that policy 
or practice to increase student involvement. It is important to note that in his theory Astin used the terms engagement and involvement as synonymous.

Moving to other more recent research, engagement is often defined as how involved or interested students appear to be in their learning (Axelson \& Flick, 2010), in other words the quality of attention they give to any learning task. Kuh et al. (2007) define it as "participation in educationally effective practices, both inside and outside the classroom, which leads to a range of measurable outcomes", Hu and Kuh (2001) define engagement as "the quality of effort students themselves devote to educationally purposeful activities that contribute directly to desired outcomes", whereas Krause and Coates (2008) see it as "the extent to which students are engaging in activities that higher education research has shown to be linked with high-quality learning outcomes". Other researchers, still, support that engagement is the "students' willingness, need, desire and compulsion to participate, and be successful in the learning process promoting higher level thinking for enduring understanding", thus focusing on the concept as intense need for participation and success (Bomia et al., 1997). Finally, some researchers see engagement as a sense of belonging: a sense of connection with what you are doing or with a place; and consider it a prerequisite for success (Stevens et al., 2018). Disengaged students are by definition alienated from what they are doing and unable to function well because alienation does not feel good; it is against one's wellbeing. According to psychologist Martin Seligman, engagement is one of the five elements of wellbeing and he argues that increased engagement may lead to Csikszentmihalyi's (1990a) state of "Flow", an unusually deep sense of connection with what you are doing, and "the loss of self-consciousness during an adsorbing activity" (Seligman, 2012).

It is clear then that while all researchers agree that engagement is important for positive learning outcomes and subsequent academic success, there is debate over the exact nature of the construct. A likely key problem is a lack of distinction between the state of engagement, its antecedents and its consequences (Kahu, 2013). Blending institutional practices with student behaviour has resulted in a lack of clear distinction between the factors that influence engagement, the measurement of engagement itself, and the consequences of engagement. For example, there is considerable overlap between items included in the active learning engagement scale and the higher order thinking outcome measure.

Interestingly, while tutors see engagement as cognitive, students see it as predominantly affective (Solomonides \& Martin, 2008). It is essential, then, that we should move on to look at the different dimensions of engagement. For this study, we will adopt $\mathrm{Hu}$ and Kuh's (2001) definition of engagement as it combines behavioural, emotional as well as cognitive dimensions of the construct which currently prevail in the literature (Trowler, 2010).

\section{What Are the Dimensions of Engagement?}

As a starting point, Astin's (1984) SI theory has five basic postulates which can 
be used to assess students' involvement and engagement as well as the effectiveness of institutional policies:

1) Students' involvement is the investment of physical and psychological energy in various objects, where the objects could be very general, for example, how a student experiences a task, or very specific, for example how a student prepares for an exam,

2) Regardless of its object, involvement occurs along a continuum, which means there are degrees of involvement for different objects at different times,

3) Involvement has both quantitative and qualitative features, therefore other factors can be measured (how many hours a student studies) and others have to be described (how interesting a student finds a specific task),

4) The amount of student learning and personal development associated with any educational program is directly proportional to the quality and quantity of student involvement in that program; and here lies the importance of involvement and subsequently of engagement in learning outcomes, and finally,

5) The effectiveness of any educational policy or practice is directly related to the capacity of that policy or practice to increase student involvement.

Moving to more current works on engagement, Trowler's (2010) research revealed the following three distinct foci of student engagement which can be identified in the literature: behavioural, cognitive and emotional. Behavioural engagement is students' practices or behaviours related to studying, whereas cognitive engagement refers to students' behaviours that reflect their thinking in terms of dedication which combines both ideas and willingness to take action. Finally, emotional engagement is a positive feeling students have for their teachers, peers, and school. It is considered that increased school engagement results in willingness to work (Fredricks et al., 2004).

However, the overwhelming majority of literature surveyed was expressly concerned with the individual student learning dimension of engagement at five levels in which all three previous foci converge:

1) student attention in learning

2) student interest in learning

3) student involvement in learning

4) student active participation in the learning process and finally

5) student involvement in the design, delivery and assessment of their learning

Regarding students' attention and commitment in the learning process, Schlechty (2002) described engaged students as students who are attracted to their work, persist in it despite challenges or obstacles and take visible delight in accomplishing their work. He also distinguishes five levels of engagement, as shown in Figure 1, depending on the combination of the degree of attention and commitment of the student:

Another notable approach is Kahu's (2013) who presents four other perspectives on engagement, and in an attempt to approach the concept more comprehensively, she added the holistic perspective. Kahu's perspectives on engagement 


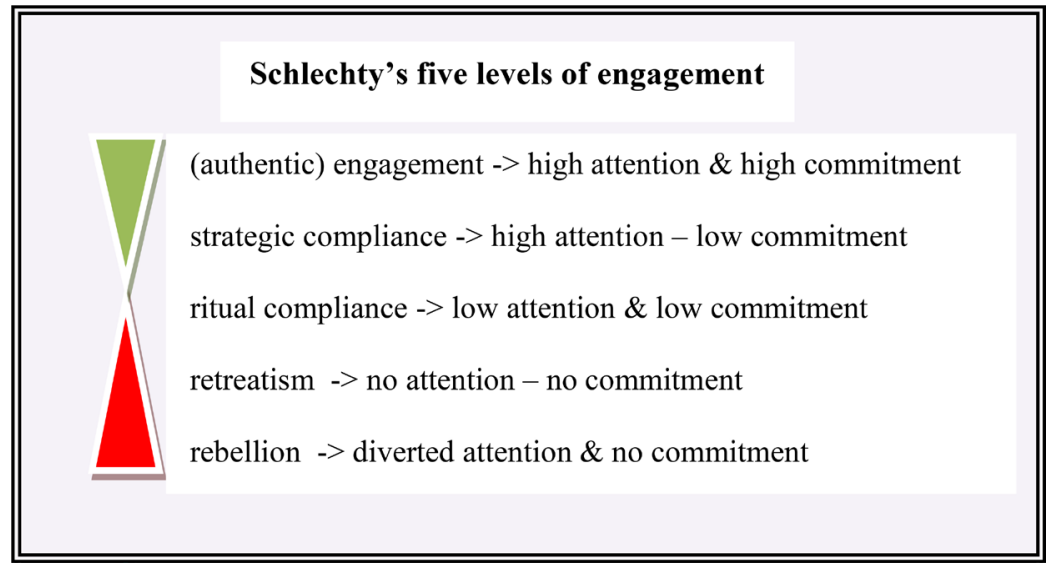

Figure 1. Levels of engagement (adapted from Schlechty, 2002).

are the behavioural, the psychological, the socio-cultural and the holistic perspective. According to Kahu, the behavioural perspective is the most widely accepted view of engagement in higher education literature. It is considered as an evolving construct that captures a range of student behaviours related to student satisfaction and achievement, including time on task, social and academic integration, and teaching practices. One of the key problems of the behavioural perspective is its dependence on surveys for measuring engagement; however it does offer some explanations for the complex picture of student behaviour. The psychological perspective is a predominant view in the school literature and considers engagement as "an internal psycho-social process that evolves over time and varies in intensity" (Kahu, 2013). The main strength of this approach, compared to the behavioural approach, is the distinction between engagement and its antecedents. Researchers in the past have proposed several overlapping aspects for engagement, such as behaviour, cognition or emotion and often even defined engagement as merely one of these, but later on it was suggested that engagement embodies all of these. Behaviour roughly shares the elements of the behavioural perspective mentioned earlier. Cognition most often refers to students' self-regulation and effective use of deep learning strategies (Fredricks et al., 2004), which is often mentioned in the behavioural perspective, but goes further to include individual characteristics, namely self-efficacy, expectations and motivation. We will revisit the concept of motivation later on in this paper. What is most important in this perspective is the affective dimension, that is the emotional intensity attached to the experience of learning and which is often overlooked (Askham, 2008). One of the greatest limitations of this perspective is the fact that there is no clear differentiation between its dimensions, which inevitably leads to inconsistencies in measuring engagement. However, the psychological perspective has great advantages mostly because now we no longer consider feeling and thinking completely different processes, but "inseparable, interwoven dimensions of human social life" (Forgas, 2000). The socio-cultural perspective studies the social or socio-political impact and how this influences student engagement and offers some insight into the notion of "disengagement". 
Finally, in Kahu's holistic perspective, there are those researchers who make an attempt to include all previous dimensions in one theory. Engagement is considered a "dynamic continuum" within different environments and locations and, again, emotion is recognised as a crucial factor (Kahu, 2013). Again, the main limitation of this perspective is the difficulty to distinguish engagement from its antecedents.

Despite the limitations of the aforementioned perspectives, each one offers valuable insight into the complex construct of student engagement within the learning environment. To sum up, the behavioural perspective looks into the importance of student behaviour; the psychological perspective defines the state of being engaged and recognises the critical dimension of affect; the socio-cultural perspective stresses the socio-cultural context in which student engagement takes place; and, finally, the holistic perspective attempts to integrate all the previous dimensions into one single theory and focus on the need to consider the student's own motivations and expectations. What should also be emphasised is that, even though all perspectives locate engagement in within the students themselves, it is critical to remember that engagement is situational; it is the interaction of the individual with the context. Furthermore, to steer clear of overlapping definitions, we should make a distinction between process and result; what is considered to be the process is not engagement, but a number of factors that influence student engagement. In fact, student engagement is the outcome, "an individual psychological state with the three dimensions... of affect, cognition and behaviour” (Kahu, 2013).

\section{Why Is Engagement Important?}

A question that arises from the previous discussion on engagement is whether the construct of engagement is of significant educational value and why. In general, education theorists and researchers do acknowledge its significant value in learning and as a result the majority of the literature is directly or indirectly concerned with improving student learning (Trowler, 2010).

Research on the idea that active engagement in the learning process has positive results can be traced back to Dewey and his introduction of active learning (Graham et al., 2007). There is now extensive literature to support that active participation in the learning process results in students' enhanced academic achievements (Aji \& Khan, 2019; Gardner et al., 1994; Narayan et al., 1990; Sanitchai \& Thomas, 2018). However, mere participation does not constitute engagement, as it is only one of its many dimensions.

Looking into literature that focuses on engagement as a more multifaceted construct, through which students develop knowledge (cognitive abilities), skills (behaviours), and dispositions (affective learning), engagement is also often related to the achievement of positive learning outcomes. This is because it partly represents the time and effort students dedicate to educational activities $(\mathrm{Hu} \&$ Kuh, 2001). 
Engagement is also considered as key for high quality learning; based on the assumption that learning is influenced by the way a learner participates in educational activities (Coates, 2005). This is mainly based on the constructivist approach which assumes that the more deeply a learner engages in educational activities designed for high quality learning outcomes, the greater the learning gains.

Some consider engagement as a proxy for quality learning (Kuh, 2009), others believe student engagement has been linked to a sense of belonging and leads to retention and academic success (Tinto, 2003). For Schlechty (2011) the reason engagement is so important is that it contributes to long-term learning, mainly because it leads to learners' persistence in learning even complex material, and commitment to apply what is learnt in new circumstances. Finally, Trowler (2010) goes as far as to advocate that "the value of engagement is no longer questioned".

It is therefore imperative that, since engagement is so valuable for the learning process, we look into how we can engage learners to achieve optimum learning outcomes. This of course depends on which engagement perspective we adopt, and which of its dimensions we consider as more vital. In this paper, we will focus on the psychological perspective and its dimension of motivation because this was what our experimental study focused on.

\section{How Is Engagement Linked to Motivation?}

First of all, it is important to stress once again that engagement is a means to an end; with it we can build improved learning outcomes. It is a state that learners should reach and teachers or instructors should help their learners to achieve. One of the tools to achieve an engaged state, a most essential one we might add, is student motivation.

Deci and Ryan (1985) and Lepper (1988) put forward a more crucial question to ask teachers and educators in general, "How do we create an environment in which this student will be motivated?" stressing hence the need for motivation before engagement can be achieved. An engaged leaner is motivated, choosing to study for a variety of reasons and purposes; for example gaining new knowledge, taking delight in a certain activity or learning how to perform a new task.

Our experimental study focused on the use of digital art and multimedia for the motivation of learners. It involved teenage Greek native speakers, all students of English as a foreign language, and looked into motivation and foreign language vocabulary learning.

Before we proceed to our experimental findings, however, it is important to define motivation as a concept.

\section{What Is Motivation and What Are the Factors That Facilitate It?}

Motivation can be defined as the student's desire to participate in the learning 
process (Brown, 2002; Dörnyei, 2001; Lewis, 2002; Rivers, 1997). As the word itself reveals, it is what "motivates", or in other words "stimulates", someone to act rather than remain a passive spectator of a situation. So, someone who feels no need or desire to act can be characterised as unmotivated, whereas someone who is activated towards a specific goal is characterised as motivated. However, a more accurate in-depth definition for motivation is extremely hard since it is one of the most complex and challenging issues educators face (Scheidecker \& Freeman, 1998). This is mainly because motivation is an abstract concept used to explain why people may behave in one way or another, and the wide range of motives underlying it may have nothing in common other than that they in fact make people behave in a certain way. It is an "umbrella" term that covers a variety of meanings (Dörnyei, 2001). Despite its complexity, the term is of great importance because it highlights one of the three basic aspects of the human mind; the aspect of "desire", as opposed to the other two aspects of "thought" and "feeling".

It is generally accepted that motivation plays a crucial role in learning and often makes the difference between learning that is superficial and learning that is deep and long lasting (Gambrell, 1996). This is probably because, in education, motivation consists of the learners' belief in their ability to carry out a specific task, the reasons and goals of the learners in doing a task, as well as their emotional response regarding carrying out the task.

Within the classroom environment, however, it is the teachers that have the power to create the environment that will lead to the best possible learning outcomes for the learners. Social psychologists distinguish three different types of power: coercive, reward-based, and referent (Wright, 1987) with punishment, reward and motivation being the basis of each type of power respectively. In motivation, individuals or institutions appeal to the commitment and interest of others. It is of importance to concern ourselves with the fostering of learner motivation, as it is considered to be the most effective and proactive power relationship (Thanasoulas, 2002).

\section{Intrinsic vs Extrinsic Motivation and Computer Games}

Motivation for learning seems to be an innate characteristic of human beings (Brown, 2002). In Deci and Ryan's (1985) groundbreaking Self-Determination Theory (SDT), they distinguish two different sources of motivation when trying to explain human behaviour: intrinsic and extrinsic. The basis of the distinction is the reason that gives rise to an action, or the goal that an action is attempting to achieve. "Over three decades of research have shown that the quality of experience and performance can be very different when one is behaving for intrinsic versus extrinsic reasons" (Ryan \& Deci, 2000). They describe intrinsic motivation as doing something because it is inherently enjoyable or interesting; that is engaging in an activity for the sake of the activity itself; for example, playing a video game in your free time because you find it enjoyable. Researchers often use 
the words "fun", "interesting", "captivating", or "enjoyable" interchangeably with "intrinsically motivating" when describing activities (Malone \& Lepper, 1987). On the other hand, extrinsic motivation, also called instrumental motivation by some scholars, is defined as doing something because it leads to a desired outcome outside the individual; for example studying hard for an exam because you want to receive good grades. The desired outcome might be to achieve a positive result (good grades) or avoid a negative result (a punishment). In education, in particular, intrinsic motivation towards knowledge is observed if an activity is performed for the pleasure or satisfaction of learning or understanding something, whereas extrinsic motivation makes students engage cognitively and behaviourally as a means to an end-high grades or a qualification, for example.

The importance of intrinsic and extrinsic motivation, comparing and contrasting the two dimensions and how they influence human behaviour, has received a lot of attention (Lepper et al., 2005; Ryan \& Deci, 2000; Vansteenkiste et al., 2006; Vansteenkiste et al., 2009) mostly because they seem to be associated so closely with learning and academic achievement. Researchers generally agree that intrinsic is better than extrinsic motivation when it comes to long term learning results (Ames, 1992; Brophy, 1987; Maehr \& Midgley, 1991; Stipek, 2002) because most of the times students will use learning strategies that process information more creatively and therefore more deeply. Human beings tend to perform better when they find tasks inherently interesting; therefore we could argue that when students are intrinsically motivated they become more involved in their learning. It might be the case that extrinsic motivation could undermine intrinsic motivation. Externally administered rewards may inhibit learning in the long run, even though they seem effective at first, because they are "addictive" (Ersöz, 2004). Some researchers go as far as supporting that extrinsic incentives should be avoided because they make students feel manipulated and controlled according to someone else's standards (Guthrie \& Alao, 1997). When students do a task for the sake of earning a reward or avoiding punishment, they will perform much less creatively because extrinsic factors are employed to persuade students to complete a task that is not their choice to begin with. This limits creativity and reduces students' interest in the learning procedure.

However, it is now accepted that students might often engage in academic tasks with both intrinsic as well as extrinsic motives. Over the last twenty years, researchers began to support the idea of a continuum between the two concepts. In their revised SDT theory, Ryan and Deci (2000) present a taxonomy of human motivation which is a continuum from amotivation (lack of motivation) to intrinsic motivation (Figure 2). As the individuals progress along this continuum towards intrinsic motivation, they exhibit a more self-determined behaviour and their motivation becomes less controlled while their autonomy in learning increases.

Intrinsic motivation is considered more powerful because it stems from needs, wants or desires from within one's self (Brown, 2002). Since intrinsic motivation 


\begin{tabular}{|c|c|c|c|c|c|}
\hline \multirow[t]{2}{*}{ Amotivation } & \multicolumn{4}{|c|}{ Extrinsic motivation } & Intrinsic \\
\hline & $\begin{array}{l}\text { External } \\
\text { regulation }\end{array}$ & Introjection & Identification & Integration & Motivation \\
\hline $\begin{array}{l}\text { Little/no perception of } \\
\text { - competence } \\
\text { - choice } \\
\text { - intention } \\
\text { - value of behaviour }\end{array}$ & $\begin{array}{l}\text { External } \\
\text { - rewards } \\
\text { - control } \\
\text { - obedience } \\
\text { - punishment }\end{array}$ & $\begin{array}{l}\text { - Focus on approval } \\
\text { from self or others } \\
\text { - Ego involvement }\end{array}$ & $\begin{array}{l}\text { - Conscious valuing } \\
\text { of activity } \\
\text { - Self-endorsement } \\
\text { of goals }\end{array}$ & $\begin{array}{l}\text { - Hierarchical } \\
\text { synthesis of goals } \\
\text { - Congruence }\end{array}$ & $\begin{array}{l}\text { - Interest } \\
\text { - Enjoyment } \\
\text { - Inherent } \\
\text { satisfaction }\end{array}$ \\
\hline Impersonal & External & $\begin{array}{c}\text { Somewhat } \\
\text { external }\end{array}$ & $\begin{array}{l}\text { Somewhat } \\
\text { internal }\end{array}$ & Internal & Internal \\
\hline
\end{tabular}

Figure 2. Motivation taxonomy based on the revised SDT, adapted from Ryan and Deci (2000).

results in high-quality learning and creativity, it is especially important to determine the factors that enhance it. So the crucial question for educators remains: How can we create an intrinsically motivating environment for students?

To this end, we will first focus on Malone's (1981a) work on intrinsically motivating environments. Malone studied computer games and attempted to answer two basic questions:

a) Why are computers so captivating? and

b) How can the features that make computer games captivating be used to make learning interesting and enjoyable?

Originally, he identified three major characteristics of intrinsically motivating instructional environments: challenge, fantasy and curiosity; and added control in 1987 (Malone \& Lepper, 1987).

Each of these characteristics is fundamental for building intrinsically motivating instructional materials.

\section{Challenge}

According to people who are highly intrinsically motivated, such as rock climbers and painters, Csikszentmihalyi describes intrinsically motivating activities as follows:

1) The activity should be structured so that the actor can increase or decrease the level of challenges he is facing, in order to match exactly his skills with the requirements for action.

2) It should be easy to isolate the activity, at least at the perceptual level, from other stimuli-external or internal—which might interfere with involvement in it.

3) There should be clear criteria for performance; one should be able to evaluate how well or how poorly one is doing at any time.

4) The activity should provide concrete feedback to the actor, so that he can tell how well he is meeting the criteria of performance (Csikszentmihalyi, 1978).

5) The activity ought to have a broad range of challenges, and possibly several qualitatively different ranges of challenge, so that the actor may obtain increa- 
singly complex information about different aspects of the self.

\section{Fantasy}

Disneyland is one of the most characteristic examples of an intrinsically motivating environment because of the fantasies it arouses in people's minds. According to Piaget (in Malone, 1981a), fantasy in children's games is "an attempt to 'assimilate' experience into existing structures in the child's mind with minimal needs to 'accommodate' to the demands of external reality".

\section{Curiosity}

Curiosity is perhaps the most fundamental feeling for human beings, a feeling that we experience from the moment we are born and accompanies us throughout our lives. Intrinsically motivating environments can continuously arouse and then satisfy our curiosity. This characteristic includes other concepts, such as novelty, complexity, surprise and incongruity (things that do not "fit" together).

\section{Control or Choice}

Control in the form of choice has a very powerful motivating effect, as people are more likely to participate in an activity if they believe they have chosen it. People will often engage even in undesirable options, just because they believe they have chosen them. It is what DeCharms (1968) describes as "personal causation"; an individual will cherish certain behaviour if they believe it is the result of their own choice. Thus, it is one of the crucial elements for creating an intrinsically motivating environment; together with immediate feedback on one's choice (Brophy, 1987). Deci and Ryan (1985), too, have documented that task engagement increases when students are provided with opportunities to make choices about their learning.

Malone's list is not exhaustive, of course. A number of other factors have been suggested as promoting motivation in the learning environment, and they are extremely valuable, especially in the case of designing instructional materials. Bowman (1982), as well as Malone (1981b) and Provenzo's (1991) research revealed some key aspects of design that support motivation. All three noted the presence of a clear goal or task, progressive balance or hierarchy of skills, as well as challenge and immediate feedback. Provenzo also stated that one of the advantages of computer games is that there are relatively few negative consequences for risk taking. All these elements are also aspects of engaged learning (Dickey, 2005). Another factor that has been empirically proven to increase motivational attractiveness of educational materials is contextualization (Cordova \& Lepper, 1996). Computer games not only provide a rich context, that arouses young learner's fantasy, but also promote cognitive traits that are consistent with children raised with technology (Prensky, 2001) as well as students' autonomy. Teachers who allow more student autonomy are more likely to have higher intrinsic motivation among their classes (Ersöz, 2004). Research into psychological and sociological benefits of play revealed that games support intrinsic motivation as well as opportunities for imitation, and learning by providing feedback, fantasy and challenges (Rieber, 1996). They achieve essential goals that cover 
specific basic needs of learners (all human beings, in fact), those for mastery when they achieve success; understanding, by satisfying their curiosity; self-expression, by allowing originality and choice; and involvement with others, by promoting cooperation and interaction.

Teachers and materials developers need to keep these characteristics in mind so that they can create an intrinsically motivating environment and optimise their students' learning potential. Focused goals, challenging tasks, clear standards, protection from adverse consequences for initial failures, affirmation of performance, collaboration with others, novelty and variety, choice and authenticity of materials are all elements that will help towards that direction. The greatest amount of learning will occur when a learning environment is designed in a way that it encourages students in active participation in various learning activities.

\section{The Experiment}

The researchers sought to determine the impact of students' intrinsic and extrinsic motivation on their engagement levels.

One hundred and seven participants, aged $11-16$ years old, 45 boys and 56 girls, took part in the experiment; all students of English as a foreign language who attended language schools in Patras, Greece.

Language schools were randomly selected from the official list of the Ministry of Education where language schools are registered. We chose three schools, two from the city centre and one from a suburb of Patras and collected about 50\% of our data from each area. All students were given a username relevant to their school and a password that was recorded and saved so that it could be used for the post-test. Once participants logged onto the platform, they completed an online personal profile questionnaire which helped us record their gender, native language, other languages they had studied, their reasons for studying English and their learning types. Following this, all participants did an online placement test, created especially for the needs of the experiment to enable us to group participants according to their language proficiency. The results of the placement test grouped participants into five different levels from Beginner (1) to Advanced (5) which correspond to CEFR levels $\mathrm{A} 1$ to $\mathrm{C} 1$ respectively. Of the one hundred and seven students, six students were excluded because of one or more of the following reasons:

1) Greek was not their native language

2) none of the target words of the study was unknown to them (advance level student)

3) they did not complete the placement test

4) they did not complete all nine activities of the platform

5) they did not complete the post-test activities which followed two to three weeks later

With regard to language proficiency, our statistical sample finally consisted of 
the following groups:

Beginner: 7

Lower Intermediate: 40

Intermediate: 45

Upper Intermediate: 9

We had expected that most of the participants would belong to the Lower Intermediate and Intermediate groups, since the ages of the participants we targeted corresponded to about 3 to 4 years of studies (C senior class to FCE class) and in fact we had asked language schools to invite students from those classes to participate in our experiment.

Since the participants were teenagers, a parental consent form was given for parents to sign before their children took part in the experiment.

The online profile questions, regarding the reasons for studying English as a foreign language, included four answers categorised as indicating extrinsic motives (nos 1 - 4) and four as intrinsic ones (nos 5 - 8). These were:

Why are you studying English?

1) to study abroad

2) to get a job

3) because my parents want me to

4) to get a language certificate

5) to speak with friends abroad or online

6) to travel

7) because I like the English language

8) because I like the English culture

The results are shown in Diagram 1. It should be noted that students were allowed to choose as many answers as they thought were relevant to them.

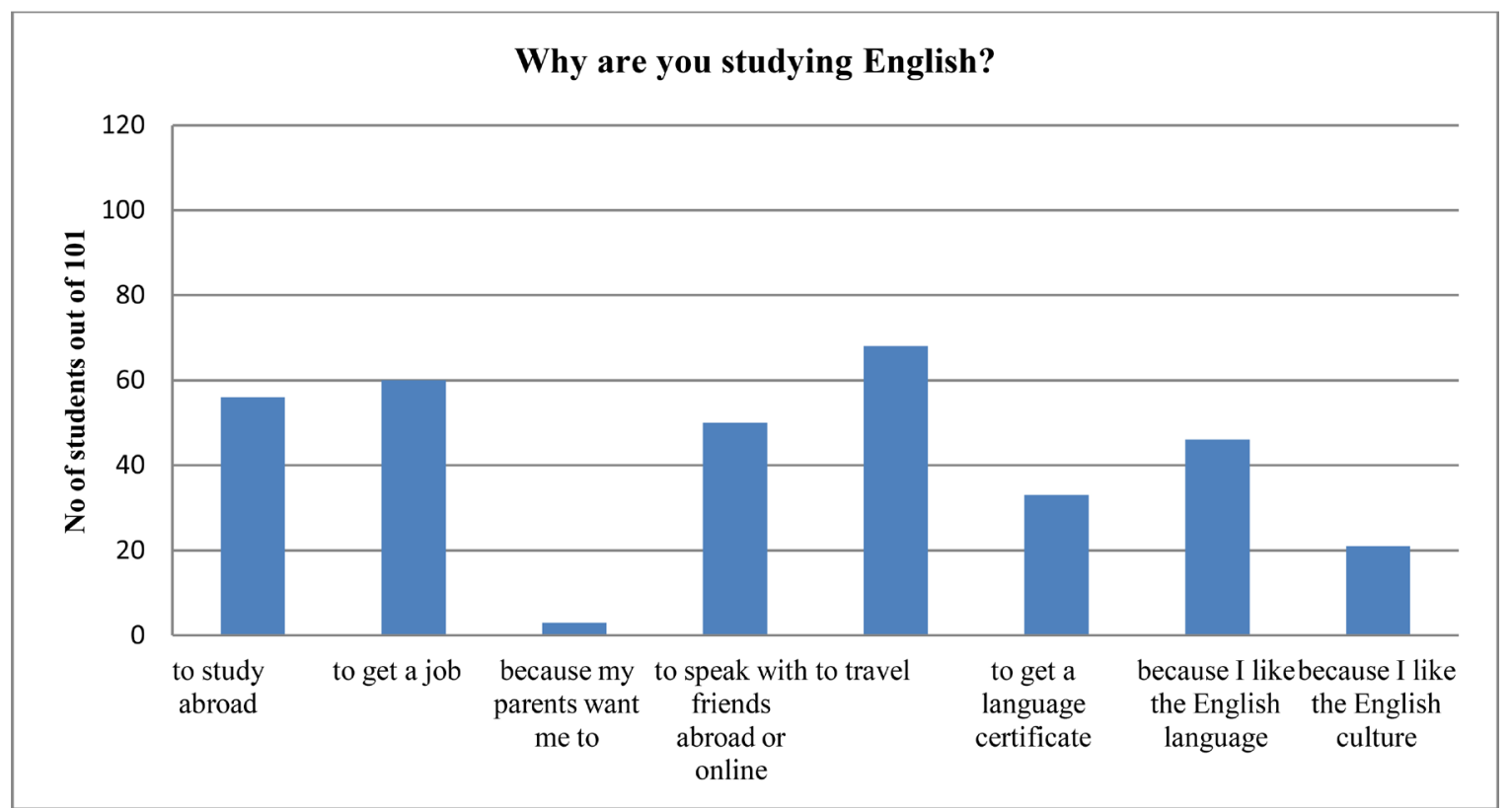

Diagram 1. Reasons for studying English. 
Then on, we assigned one point for each of the questions investigating the students' reasons for studying English and grouped participants into three categories:

Group 1: intrinsic motives higher than extrinsic motives

Group 2: intrinsic motives equal to extrinsic motives

Group 3: intrinsic motives lower than extrinsic motives

The results of the categorisation were as follows: out of 101 participants, 36 participants in group 1, 33 participants in group 2 and 32 participants in group 3.

The participants were given access to a specially-built platform with a number of online activities and we measured the times students devoted to each activity as well as the words they looked up, or listened to, during the activities. The platform was part of a bigger thesis experiment on foreign language vocabulary acquisition with the use of an online film extract; but for this paper we will focus on issues of motivation and engagement on the following two activities:

Activity 03: a 3-minute video from NASA on extraterrestrial life (which was the broader topic of the entire platform)

Activity 06: the summary of a film on aliens and extraterrestrial life (Independence Day, 1999)

For activity 03, we recorded the time each student spent on it; whereas for activity 06 we recorded the time spent on reading the summary, as well as the number of words students looked up while reading it. In activity 06 , the platform enabled students to hit on specific words or phrases to look them up on an online dictionary. Our null hypothesis for this experiment was that there would be no significant difference between the three groups regarding those measurements. We assume that more time spent on an activity or more words looked up during the activities indicate more engagement on the part of the students. The results were analysed using the one-way analysis of variance (ANOVA) test.

Levene's Test (Levene, 1960) was used to check the assumption of homogeneity of variance to make sure groups were homogenous. That means checking whether there were equal variances among the group in a distribution (Pallant, 2005), and throughout the data, especially where there are several groups of participants. In other words, each of these samples should come from populations with the same variance. For the homogeneity of variance to be assumed, the $\mathrm{p}$ value should be greater than.05 ( $p>0.05$ ) (Field, 2009; Pallant, 2005). This alpha level was met when checking Levene's Test throughout our data analysis, even though at one occasion it was marginal.

\section{Findings}

For this part of our experiment, our research question (RQ) was: Do learners who are more intrinsically than extrinsically motivated become more engaged in the activities they are given? Our Null Hypothesis (Ho) was that the type of motivation (extrinsic or intrinsic) of our participants would not affect the time 
spent on the activities or the words they looked up in them, thus indicating the same degree of engagement in those activities.

\section{Activity 03}

The time each participant spent on the video was recorded in seconds. It should be noted that participants could watch the video again if they wanted to, and choose the kind of subtitling they preferred. They could also choose to proceed to the next activity at any time, even without watching the entire video, which lasted 197 seconds ( 3 min and 17 seconds).

For this activity, we started with comparing groups 1 and 3, as we believed they would give us the most interesting results. The individual times per participant for groups 1 and 3 are shown in Diagram 2.

Descriptives for the two groups were as follows in Table 1.

The one-side ANOVA test for groups 1 and 3 produced the following results (Table 2).

The ANOVA test indicates there is a statistically significant relationship between participants with higher intrinsic motivation and time spent on the activity in question: ANOVA F $=4.802 \mathrm{~F}_{\text {crit }}=3.99, p=0.032<0.05$.

The respective ANOVA test between groups 2 and 3 (equal intrinsic/extrinsic

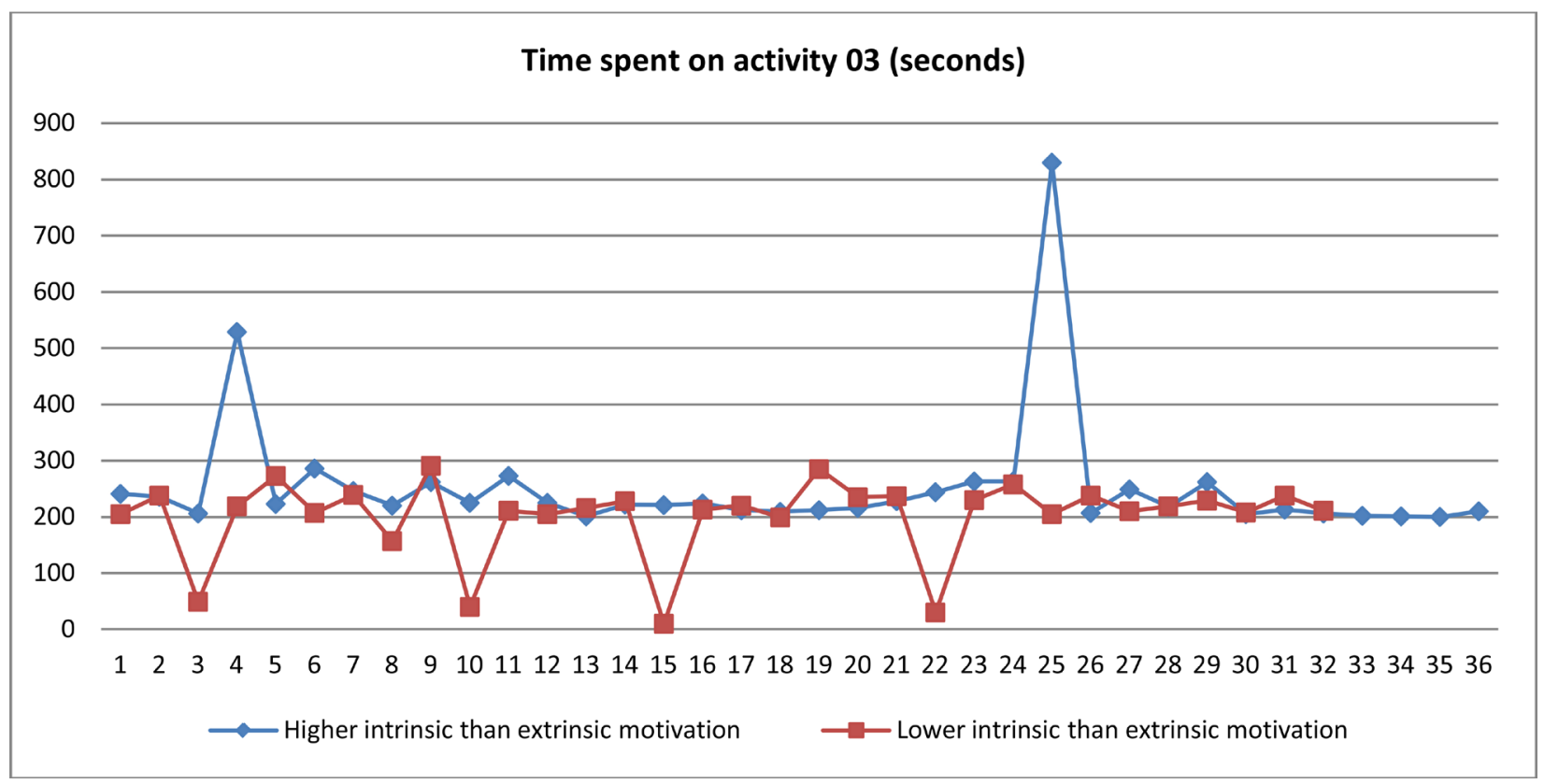

Diagram 2. Time spent on activity 03 for groups 1 and 3 in seconds.

Table 1. Descriptives of groups 1 and 3 for time spent on activity 03 .

\begin{tabular}{|c|c|c|c|c|c|c|c|c|}
\hline \multirow[b]{2}{*}{ GRADE } & \multirow{2}{*}{$\mathbf{N}$} & \multirow{2}{*}{ Mean } & \multirow{2}{*}{$\begin{array}{c}\text { Std. } \\
\text { Deviation }\end{array}$} & \multirow{2}{*}{ Std. Error } & \multicolumn{2}{|c|}{ 95\% Confidence Interval for Mean } & \multirow{2}{*}{ Minimum } & \multirow{2}{*}{ Maximun } \\
\hline & & & & & Lower Bound & Upper Bound & & \\
\hline group1 & 36 & 252.500 & 113.3302 & 18.8884 & 214.155 & 290.845 & 200.0 & 830.0 \\
\hline group3 & 32 & 201.656 & 70.1177 & 12.3952 & 176.376 & 226.936 & 10.0 & 291.0 \\
\hline Total & 68 & 228.574 & 98.1726 & 11.9052 & 204.811 & 252.336 & 10.0 & 830.0 \\
\hline
\end{tabular}


motivation vs lower intrinsic motivation) also revealed a statistically significant difference favouring group 2 with $\mathrm{F}=5.53\left(\mathrm{~F}_{\text {crit }}=3.99\right), p=0.022<0.05$.

\section{Activity 06}

Here, too, we recorded the time participants spent reading the film summary. In this activity, however, there was an additional feature. Participants could click on words or phrases in the text and they were directed to an online dictionary (Wordreference) to look up the meaning of each word or phrase. Our online platform recorded all the words users clicked on.

The following diagram shows the time each participant spent on the activity (Diagram 3).

We compared all three groups, with the following characteristics (Table 3).

In our test, however, the participants of the three groups were not significantly

Table 2. ANOVA test for groups 1 and 3, time spent on activity 03 .

\begin{tabular}{cccccc}
\hline GRADE & Sum of Squares & df & Mean Square & F & Sig. \\
\hline Between Groups & $43,794.414$ & 1 & $43,794.414$ & 4.802 & 0.032 \\
Within Groups & $601,942.219$ & 66 & 9120.337 & & \\
Total & $645,736.632$ & 67 & & & \\
\hline
\end{tabular}

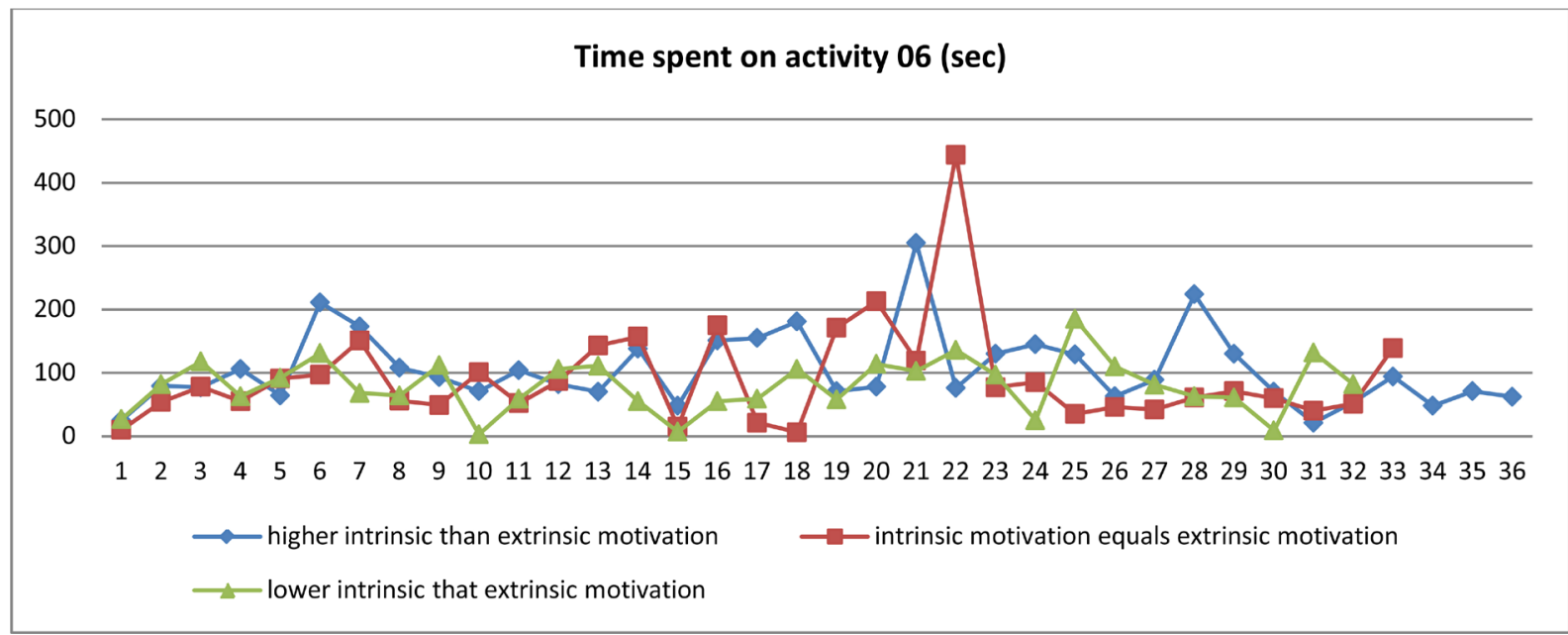

Diagram 3. Time participants spent on activity 06 .

Table 3. Descriptive of groups 1, 2 and 3 for time spent on activity 06.

\begin{tabular}{|c|c|c|c|c|c|c|c|c|}
\hline \multicolumn{9}{|c|}{ One-side ANOVA } \\
\hline \multirow{2}{*}{ GRADE } & \multirow[t]{2}{*}{$\mathbf{N}$} & \multirow{2}{*}{ Mean } & \multirow{2}{*}{$\begin{array}{c}\text { Std. } \\
\text { Deviation }\end{array}$} & \multirow{2}{*}{$\begin{array}{l}\text { Std. } \\
\text { Error }\end{array}$} & \multicolumn{2}{|c|}{$\begin{array}{l}\text { 95\% Confidence Interval } \\
\text { for Mean }\end{array}$} & \multirow{2}{*}{ Min } & \multirow{2}{*}{$\operatorname{Max}$} \\
\hline & & & & & Lower Bound & Upper Bound & & \\
\hline group1 & 36 & 105.44 & 59.228 & 9.871 & 85.40 & 125.48 & 21.0 & 305.0 \\
\hline group2 & 33 & 92.48 & 81.554 & 14.196 & 63.56 & 121.40 & 6.0 & 444.0 \\
\hline group3 & 32 & 80.40 & 41.486 & 7.333 & 65.48 & 95.39 & 3.0 & 185.0 \\
\hline Total & 101 & 93.28 & 63.213 & 6.290 & 80.80 & 105.76 & 3.0 & 444.0 \\
\hline
\end{tabular}


different: $p=0.267$ (Table 4).

As a next step, we compared groups $1 \& 3$, that is the participants with higher intrinsic than extrinsic motivation compared to the participants with lower intrinsic than extrinsic motivation (Table 5).

In this case, the ANOVA results indicated a statistically significant relationship between the groups and their motivational profiles, even though a marginal one $\mathrm{p}=0.05$ (Table 6).

Turning to the other feature we had at our disposal in activity 06, Diagram 4

Table 4. ANOVA test for groups 1, 2 and 3 for time spent on activity 06 .

\begin{tabular}{cccccc}
\hline GRADE & Sum of Squares & df & Mean Square & F & Sig. \\
\hline Between Groups & $10,625.667$ & 2 & 5312.833 & 1.339 & 0.267 \\
Within Groups & $388,973.006$ & 98 & 3969.112 & & \\
Total & $399,598.673$ & 100 & & & \\
\hline
\end{tabular}

Table 5. Descriptives of groups 1 and 3 for time spent on activity 06 .

\begin{tabular}{|c|c|c|c|c|c|c|c|c|}
\hline \multicolumn{9}{|c|}{ One-side ANOVA } \\
\hline \multirow{2}{*}{ GRADE } & \multirow[t]{2}{*}{$\mathbf{N}$} & \multirow[t]{2}{*}{ Mean } & \multirow{2}{*}{$\begin{array}{c}\text { Std. } \\
\text { Deviation }\end{array}$} & \multirow{2}{*}{$\begin{array}{l}\text { Std. } \\
\text { Error }\end{array}$} & \multicolumn{2}{|c|}{$\begin{array}{l}\text { 95\% Confidence Interval } \\
\text { for Mean }\end{array}$} & \multirow[t]{2}{*}{ Min } & \multirow[t]{2}{*}{$\operatorname{Max}$} \\
\hline & & & & & Lower Bound & Upper Bound & & \\
\hline group1 & 36 & 105.444 & 59.2281 & 9.8714 & 85.405 & 125.484 & 21.0 & 305.0 \\
\hline group3 & 32 & 80.438 & 41.4868 & 7.3339 & 65.480 & 95.395 & 3.0 & 185.0 \\
\hline Total & 68 & 93.676 & 52.7920 & 6.4020 & 80.898 & 106.455 & 3.0 & 305.0 \\
\hline
\end{tabular}

Table 6. One-side ANOVA test for groups 1 and 3 for time spent on activity 06.

\begin{tabular}{cccccc}
\hline GRADE & Sum of Squares & df & Mean Square & F & Sig. \\
\hline Between Groups & $10,594.118$ & 1 & 10594.118 & 3.970 & 0.050 \\
Within Groups & $176,134.764$ & 66 & 2668.709 & & \\
Total & $186,728.882$ & 67 & & \\
\hline
\end{tabular}

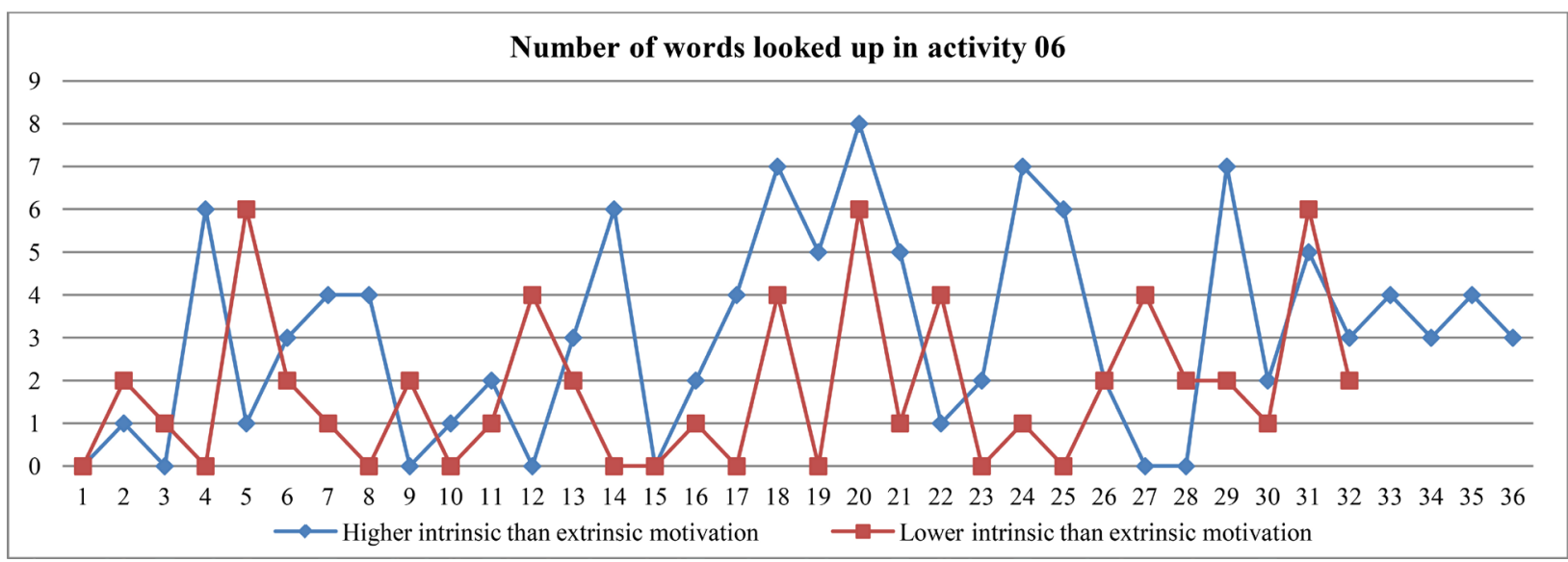

Diagram 4. Number of words looked up during activity 06. 
shows the number of words looked up by participants in experimental groups 1 and 3. Again, we chose to compare these two groups because we believed that the greater the difference between the intrinsic and extrinsic motivation of the participants, the more statistically significant the results would be.

Our findings were as shown in Table $7 \&$ Table 8.

Our one-side ANOVA test revealed that participants in group 1 looked up more words than those in group 3 , at a level of significance $p=0.016<0.05$.

\section{Conclusion and Discussion}

The first goal of this study was to look into the concepts of engagement and how this is enhanced by intrinsic or extrinsic motivation. Even though there is a consensus on engagement playing a crucial role in positive learning outcomes, there seems to be great difficulty in defining the construct. For this paper, we adopted the definition of $\mathrm{Hu}$ and $\mathrm{Kuh}$ (2001): "the quality of effort students themselves devote to educationally purposeful activities that contribute directly to desired outcomes". Intrinsic motivation denotes the performance of an activity out of enjoyment or interest. It is what we simply call doing something for fun or entertainment, or just because it seems interesting to us. Extrinsic motivation, on the other hand, arises from other sources, outside ourselves; it might be something imposed on us from someone else in the form of a reward, or because we need to please someone else, or avoid a negative consequence. Extrinsic motivation does not produce desire to engage with something for its own sake. Over the last years, the dichotomy between intrinsic and extrinsic motivation seems to have shifted and it is now believed this is rather a continuum and learners' motivation might lie somewhere in between (Ryan \& Deci, 2000). It could be argued that intrinsic and extrinsic motivation can complement each other.

In our experimental study, we divided our participants into three groups, thus

Table 7. Descriptives of groups 1 and 3 for words looked up in activity 06.

\begin{tabular}{|c|c|c|c|c|c|c|c|c|}
\hline \multicolumn{9}{|c|}{ One-side ANOVA } \\
\hline \multirow[t]{2}{*}{ GRADE } & \multirow[t]{2}{*}{$\mathbf{N}$} & \multirow[t]{2}{*}{ Mean } & \multirow{2}{*}{$\begin{array}{c}\text { Std. } \\
\text { Deviation }\end{array}$} & \multirow{2}{*}{$\begin{array}{l}\text { Std. } \\
\text { Error }\end{array}$} & \multicolumn{2}{|c|}{$\begin{array}{l}\text { 95\% Confidence Interval } \\
\text { for Mean }\end{array}$} & \multirow[t]{2}{*}{ Min } & \multirow[t]{2}{*}{$\operatorname{Max}$} \\
\hline & & & & & Lower Bound & Upper Bound & & \\
\hline group1 & 36 & 3.083 & 2.394 & 0.399 & 2.273 & 3.894 & 0.0 & 8.0 \\
\hline group3 & 32 & 1.781 & 1.879 & 0.332 & 1.104 & 2.459 & 0.0 & 6.0 \\
\hline Total & 68 & 2.471 & 2.249 & 0.272 & 1.926 & 3.015 & 0.0 & 8.0 \\
\hline
\end{tabular}

Table 8. ANOVA test for groups 1 and 3 for words looked up in activity 06 .

\begin{tabular}{cccccc}
\hline GRADE & Sum of Squares & df & Mean Square & F & Sig. \\
\hline Between Groups & 28.722 & 1 & 28.722 & 6.111 & 0.016 \\
Within Groups & 310.219 & 66 & 4.700 & & \\
Total & 338.941 & 67 & & \\
\hline
\end{tabular}


also considering those participants driven equally by intrinsic as well as extrinsic motives (group 2), and so taking into account Ryan and Deci's continuum. The results, however, were clearer and more statistically significant when we compared groups 1 and 3, as one might expect. In our findings, group 1 participants, who were more intrinsically than extrinsically motivated, devoted more time and effort to the activities at hand in all three cases we examined. It is also worth noticing, that the results of time spent on activity 03 were more statistically significant than time spent on activity 06 . We believe that this is because of the nature of the activities in question: video versus reading a text. Videos help increase students' motivation (Bravo et al., 2011), and in our case this meant further enhancing participants' intrinsic motivation, since participants only watched the video for their amusement or out of interest and without any kind of penalty for not watching it nor because of the promise of any extrinsic rewards. Finally, students who were more intrinsically motivated did much more work on unknown vocabulary and looked up more new words. Perhaps here, too, the online search tool was a strong factor, as it gave students a sense of control and choice over their learning and aroused their curiosity, thus enhancing their intrinsic motivation even further.

The present study however has its limitations. Intrinsic and extrinsic motivation were measured by a specific set of questions, and perhaps a different set might yield different results. We used a specific video with a certain vocabulary set, which students saw on one occasion, that is, during the experiment on a specific day. More viewings of this video at different times throughout their course might give us even more concrete results. Alternatively, other videos might produce different results. More significantly, it is not possible for us to know how truthful the students' answers were, nor how seriously they answered the profile questions. Another issue is that it does not take into account the participants' gender, affinity towards the language or different learning types and how these might affect students' engagement. As this is part of a $\mathrm{PhD}$ thesis, more work will be done into these issues with the use of the data that has been collected from the entire experiment, with includes ten activities in total and a preand post-test looking into long term vocabulary retention.

In the light of our findings so far, however, we would recommend teachers invest some of their time at the beginning of any course to investigate their students' motives, independently of their age or background. It is often the case that, especially in the case of young students, teachers take their students' interest or motivation for granted and frequently do not question it at all. It's best if teachers look into what their students' personal reasons for attending the classes are, if any. As a good practice, we would suggest teachers record the motivational profiles of their students and make efforts to increase their motivation, focusing on intrinsic motivation in particular. Discussing with the students about the reasons for learning a foreign language, and the specific foreign language of their course in particular, could raise their enthusiasm and commitment, and increase 
desirable outcomes. Moreover, we recommend using materials that boost one or more of the aspects that enhance motivation: fantasy, curiosity and choice, or creating materials for their classes with these aspects in mind.

Summing up our discussion on active engagement, in any classroom environment, it is the teacher's role to help increase students' motivation in learning, especially its intrinsic dimension. One of the ways to achieve this is to create an intrinsically, or partly intrinsically, motivating environment, be it face-to-face or online, with the use of specially prepared instructional materials. Teachers may choose "toys" or "tools" for their instruction, with the sense of Malone \& Lepper (1987); where "toys" are intrinsic motivational materials or methods and "tools" extrinsically ones. With these "toys and tools" we can develop new teaching methods and materials to fit our classes' motivational profiles and ensure better and more long-lasting learning results.

\section{Conflicts of Interest}

The authors declare no conflicts of interest regarding the publication of this paper.

\section{References}

Aji, C., \& Khan, J. (2019). The Impact of Active Learning on Students' Academic Performance. Open Journal of Social Sciences, 7, 204-211. https://doi.org/10.4236/jss.2019.73017

Ames, C. (1992). Classrooms: Goals, Structures, and Student Motivation. Journal of Educational Psychology, 84, 261-271. https://doi.org/10.1037/0022-0663.84.3.261

Askham, P. (2008). Context and Identity: Exploring Adult Learners' Experiences of Higher Education. Journal of Further and Higher Education, 32, 85-97. https://doi.org/10.1080/03098770701781481

Astin, A. W. (1984). Student Involvement: A Developmental Theory for Higher Education. Journal of College Student Personnel, 25, 297-308.

Axelson, R. D., \& Flick, A. (2010). Defining Student Engagement. Change: The Magazine of Higher Learning, 43, 38-43. https://doi.org/10.1080/00091383.2011.533096

Bomia, L. et al. (1997). The Impact of Teaching Strategies on Intrinsic Motivation (pp. 1-28). Opinion Papers.

Bowman, R. F. (1982). A "Pac-Man" Theory of Motivation: Tactical Implications for Classroom Instruction. Educational Technology, 22, 14-16.

Bravo, E. et al. (2011). Video as a New Teaching Tool to Increase Student Motivation. 2011 IEEE Global Engineering Education Conference (EDUCON), Amman, Jordan, 4-6 April 2011, 638-642. https://doi.org/10.1109/EDUCON.2011.5773205

Brophy, J. (1987). Synthesis of Research on Strategies for Motivating Students to Learn. Educational Leadership, 45, 40-48.

Brown, D. H. (2002). English Language Teaching in the "Post-Method" Era: Toward Better Diagnosis, Treatment, and Assessment. In J. C. Richards, \& W. A. Renandya (Eds.), Methodology in Language Teaching: An Anthology of Current Practice (pp. 9-18). Cambridge, UK: CUP. https://doi.org/10.1017/CBO9780511667190.003

Coates, H. (2005). The Value of Student Engagement for Higher Education Quality As- 
surance. Quality in Higher Education, 11, 25-36. https://doi.org/10.1080/13538320500074915

Cordova, D. I., \& Lepper, M. R. (1996). Intrinsic Motivation and the Process of Learning: Beneficial Effects of Contextualization, Personalization, and Choice. Journal of Educational Psychology, 88, 715-730. https://doi.org/10.1037/0022-0663.88.4.715

Csikszentmihalyi, M. (1978). Intrinsic Rewards and Emergent Motivation. In M. R. L. A. D. Greene (Ed.), The Hidden Costs of Reward (pp. 205-216). Morristown, NJ: Lawrence Erlbaum Associates.

Csikszentmihalyi, M. (1990a). Flow: The Psychology of Optimal Experience. Journal of Leisure Research, 24, 93-94. https://doi.org/10.1080/00222216.1992.11969876

Csikszentmihalyi, M. (1990b). Literacy and Intrinsic Motivation. Daedalus, 119(1), 115-140.

DeCharms, C. R. (1968). Personal Causation: The Internal Affective Determinants of Behavior. New York: Academic Press.

Deci, E. L., \& Ryan, R. M. (1985). Intrinsic Motivation and Self-Determination in Human Behavior. New York: Plenum Press. https://doi.org/10.1007/978-1-4899-2271-7

Dickey, M. (2005). Engaging by Design: How Engagement Strategies in Popular Computer and Video Games Can Inform Instructional Design. Educational Technology Research and Development, 53, 67-83. https://doi.org/10.1007/BF02504866

Dörnyei, Z. (2001). Motivational Strategies in the Language Classroom. Cambridge, UK: CUP. https://doi.org/10.1017/CBO9780511667343

Ersöz, A. (2004). Intrinsic Motivation in English Language Teaching. Education and Science, 29, 67-71.

Field, A. P. (2009). Discovering Statistics Using SPSS (3rd ed.). Los Angeles [i.e. Thousand Oaks, CA]; London: SAGE Publications.

Forgas, J. P. (2000). Feeling and Thinking: The Role of Affect in Social Cognition. New York, NY: Cambridge University Press.

Fredricks, J. A. et al. (2004). School Engagement: Potential of the Concept, State of the Evidence. Review of Educational Research, 74, 59-109. https://doi.org/10.3102/00346543074001059

Gambrell, L. B. (1996). Creating Classroom Cultures That Foster Reading Motivation. The Reading Teacher, 50, 14-25.

Gardner, R. et al. (1994). Effects of Response Cards on Student Participation and Academic Achievement: A Systematic Replication with Inner-City Students during Whole-Class Science Instruction. Journal of Applied Behavior Analysis, 27, 63-71. https://doi.org/10.1901/jaba.1994.27-63

Graham, C. et al. (2007). Empowering or Compelling Reluctant Participators Using Audience Response Systems. Active Learning in Higher Education, 8, 233-258. https://doi.org/10.1177/1469787407081885

Guthrie, J. T., \& Alao, S. (1997). Designing Contexts to Increase Motivations for Reading. Educational Psychologist, 32, 95-105. https://doi.org/10.1207/s15326985ep3202 4

Hu, S., \& Kuh, G. D. (2001). Being (Dis)Engaged in Educationally Purposeful Activities: The Influences of Student and Institutional Characteristics. Research in Higher Education, 43, 555-575. https://doi.org/10.1023/A:1020114231387

Kahu, E. R. (2013). Framing Student Engagement in Higher Education. Studies in Higher Education, 38, 758-773. https://doi.org/10.1080/03075079.2011.598505

Kidd, C., \& Hayden, B. Y. (2015). The Psychology and Neuroscience of Curiosity. Neu- 
ron, 88 , 449-460. https://doi.org/10.1016/j.neuron.2015.09.010

Krause, K. L., \& Coates, H. (2008). Students' Engagement in First-Year University. Assessment \& Evaluation in Higher Education, 33, 493-505. https://doi.org/10.1080/02602930701698892

Kuh, G. (2009). What Student Affairs Professionals Need to Know about Student Engagement. Journal of College Student Development, 50, 683-706. https://doi.org/10.1353/csd.0.0099

Kuh, G. D. et al. (Eds.) (2007). Piecing Together the Student Success Puzzle: Research, Propositions, and Recommendations. ASHE Higher Education Report, 32, 1-182.

Lepper, M. R. (1988). Motivational Considerations in the Study of Instruction. Cognition and Instruction, 5, 289-309. https://doi.org/10.1207/s1532690xci0504 3

Lepper, M. R. et al. (2005). Intrinsic and Extrinsic Motivational Orientations in the Classroom: Age Differences and Academic Correlates. Journal of Educational Psychology, 97, 184-196. https://doi.org/10.1037/0022-0663.97.2.184

Levene, H. (1960). Robust Tests for Equality of Variances. In I. Olkin (Ed.), Contributions to Probability and Statistics (pp. 278-292). Palo Alto, CA: Stanford University Press.

Lewis, M. (2002). Classrooom Management. In J. C. Richards, \& W. A. Renandya (Eds.), Methodology in Language Teaching: An Anthology of Current Practice (pp. 40-48). Cambridge, UK: CUP.

Maehr, M. L., \& Midgley, C. (1991). Enhancing Student Motivation: A Schoolwide Approach. Educational Psychologist, 26, 399-427. https://doi.org/10.1207/s15326985ep2603\&4 9

Malhiwsky, D. (2010). Student Achievement Using Web 2.0 Technologies: A Mixed Methods Study 58. https://digitalcommons.unl.edu/cehsdiss/58

Malone, T. (1981a). Toward a Theory of Intrinsically Motivating Instruction. Cognitive Science, 5, 333-369. https://doi.org/10.1207/s15516709cog0504 2

Malone, T. (1981b). What Makes Computer Games Fun? Human Interface and the User Interface. https://doi.org/10.1145/800276.810990

Malone, T. W., \& Lepper, M. R. (1987). Making Learning Fun: A Taxonomy of Intrinsic Motivations for Learning. In R. E. Snow, \& M. J. Farr (Eds.), Aptitude, Learning, and Instruction Volume 3: Cognitive and Affective Process Analyses (pp. 223-253). Hillsdale, NJ: Lawrence Erlbaum Associates.

Narayan, J. et al. (1990). Using Response Cards to Increase Student Participation in an Elementary Classroom. Journal of Applied Behavior Analysis, 23, 483-490. https://doi.org/10.1901/jaba.1990.23-483

Pallant, J. (2005). SPSS Survival Manual: A Step by Step Guide to Data Analysis Using SpSS for Windows (Version 12). Crow's Nest, AUS: Allen \& Unwin.

Parsons, J., \& Taylor, L. (2011). Improving Student Engagement. Current Issues in Education, 14, 1-32.

Prensky, M. (2001). Digital Game-Based Learning (p. 1). New York: McGraw-Hill. https://doi.org/10.1145/950566.950596

Provenzo Jr., E. F. (1991). Video Kids: Making Sense of Nintendo. Cambridge, MA: Harvard University Press. https://doi.org/10.4159/harvard.9780674422483

Rieber, L. P. (1996). Seriously Considering Play: Designing Interactive Learning Environments Based on Blending Microworlds, Simulations, and Games. Educational Technology Research and Development, 44, 43-58. https://doi.org/10.1007/BF02300540 
Rivers, W. (1997). Principles of Interactive Language Teaching. http://edevaluator.org/rivers/10Principles $0 . \mathrm{html}$

Ryan, R. M., \& Deci, E. L. (2000). Intrinsic and Extrinsic Motivations: Classic Definitions and New Directions. Contemporary Educational Psychology, 25, 54-67. https://doi.org/10.1006/ceps.1999.1020

Sanitchai, P., \& Thomas, D. (2018). The Relationship of Active Learning and Academic Achievement among Provincial University Students in Thailand. APHEIT International Journal, 7, 47-61.

Scheidecker, D. D., \& Freeman, W. B. (1998). Bringing out the Best in Students: How Legendary Teachers Motivate Kids. Thousand Oaks, CA: Corwin Press Inc.

Schlechty, P. C. (2002). Working on the Work. San Francisco, CA: Jossey-Bass.

Schlechty, P. C. (2011). Engaging Students: The Next Level of Working on the Work. San Francisco, CA: Jossey-Bass.

Seligman, M. (2012). Flourish: A Visionary New Understanding of Happiness and Well-Being. New York, NY: Free Press.

Solomonides, I. P., \& Martin, P. (2008). “All This Talk of Engagement Is Making Me Itch": An Investigation into the Conceptions of "Engagement" Held by Students and Tutors. In L. Hand, \& B. Colin (Eds.), Student Engagement (pp. 13-18). London: Staff and Educational Development Association.

Stevens, R. et al. (2018). Cultivating Student Engagement-Part 1. Scan, 37, 26-31.

Stipek, D. (2002). Motivation to Learn: From Theory to Practice (4th ed.). Needham Heights, MA: Allyn \& Bacon.

Thanasoulas, D. (2002). Motivation and Motivating in the Foreign Language Classroom. The Internet TESL Journal, VIII. http://iteslj.org/Articles/Thanasoulas-Motivation.html

Tinto, V. (2003). Promoting Student Retention Through Classroom Practice. Paper presented at the Enhancing Student Retention: Using International Policy and Practice, Amsterdam.

https://www.researchgate.net/publication/255589128 Promoting Student Retention Through Classroom Practice

Trowler, V. (2010). Student Engagement Literature Review. The Higher Education Academy, 11, 1-15.

Vansteenkiste, M. et al. (2006). Intrinsic versus Extrinsic Goal Contents in Self-Determination Theory: Another Look at the Quality of Academic Motivation. Educational Psychologist, 41, 19-31. https://doi.org/10.1207/s15326985ep4101 4

Vansteenkiste, M. et al. (2009). "What Is the Usefulness of Your Schoolwork?”: The Differential Effects of Intrinsic and Extrinsic Goal Framing on Optimal Learning. Theory and Research in Education, 7, 155-163. https://doi.org/10.1177/1477878509104320

Wright, T. (1987). Roles of Teachers \& Learners. Oxford: OUP. 